\title{
O PERIÓDICO TEIAS COMO ESPAÇO DE PRODUÇÃO NO CAMPO DA EDUCAÇÃO, CURRÍCULO E FORMAÇÃO DOCENTE ${ }^{1}$
}

\author{
Terezinha Maria Schuchter ${ }^{(*)}$ \\ Juliana Paoliello ${ }^{(* *)}$ \\ Nilcea Elias Rodrigues Moreira ${ }^{(* *)}$
}

Neste estudo, objetivamos analisar as práticas discursivas veiculadas no periódico Teias nos anos de 2013 a 2016, nas edições apresentadas em forma de dossiê organizadas pela Associação Brasileira de Currículo (ABdC). Os eixos de análise foram assim constituídos: temáticas dos volumes e dos artigos, autores e sua filiação institucional, conceitos e palavras-chave, abordagem teórico-epistemológica, abordagem metodológica, autores referenciados e principais conceitos tomados desses autores.

Como abordagem metodológica, utilizamos a análise da discursividade a partir do mapeamento cartográfico-discursivo. Foram selecionadas quatro edições com as seguintes temáticas e quantidade de artigos (Quadro 1):

\section{Quadro 1. Temáticas dos dossiês e quantitativo de artigos $^{2}$}

\begin{tabular}{|l|l|l|}
\hline $\begin{array}{l}\text { V. 14, n. } 33 \text { (2013): Currículo, } \\
\text { conhecimento e experiências }\end{array}$ & Editorial & 8 artigos \\
\hline $\begin{array}{l}\text { V. 15, n. } 39 \text { (2014): Currículo, políticas e } \\
\text { trabalho docente }\end{array}$ & Apresentação & 7 artigos \\
\hline $\begin{array}{l}\text { V. 16, n. } 43 \text { (2015): A produção biopolítica } \\
\text { das definições curriculares no Brasil } \\
\text { contemporâneo }\end{array}$ & Editorial & 5 artigos \\
\hline Continua & & \\
\hline $\begin{array}{l}\text { V. 17, n. } 47 \text { (2016): O avanço do } \\
\text { conservadorismo nas políticas curriculares }\end{array}$ & Editorial & 6 artigos \\
\hline Total & 26 artigos \\
\hline
\end{tabular}

A opção por essa abordagem metodológica se justifica pelo fato de a pesquisa buscar tecer relações entre as práticas discursivas, a partir dos enunciados expressos no periódico Teias, compondo “[...] relações de vizinhança e/ou de afastamento entre eles, cartografando, nesse sentido,

\footnotetext{
${ }^{1}$ Este estudo é subproduto do projeto de pesquisa-base, coordenado pela professora Dra Janete Magalhães Carvalho, intitulado Discursividade sobre currículo da comunidadeacadêmicocientífica vinculadas as associações de campo e veiculada em periódicos nacionais e internacional, cadastrado no CNPq.

${ }^{(*)}$ Professora Associada do Centro de Educação da Universidade Federal do Espírito Santo

${ }^{(* *)}$ Doutoranda em Educação do Programa de Pós-Graduação em Educação da Universidade Federal do Espírito Santo

${ }^{(* *)}$ Doutoranda em Educação do Programa de Pós-Graduação em Educação da Universidade Federal do Espírito Santo

${ }^{2}$ Todos os gráficos e tabelas foram elaborados pelas autoras.
} 
tramas, diagramas e redes que no período analisado engendram regimes de verdade" (CARVALHO, 2016, p. 5).

A compreensão desse engendramento de regimes de verdade é importante por se constituírem como “[...] verdadeiras redes histórico-culturais que funcionam como uma espécie de 'modelo/molde' para a produção de determinados significados e determinadas verdades historicamente localizados” (CARVALHO, 2016, p. 6).

Apoiando-se em Foucault (1986), Carvalho (2016, p. 6) destaca que esses regimes de verdade, ao se constituírem como uma formação discursiva, acabam por funcionar

[...] como uma rede de relação entre enunciados que configuram campos discursivos específicos, formados como um acontecimento que permite a expressão de certas ideias apreendidas socialmente e avaliadas como verdadeiras ou falsas para uma determinada época e um espaço definido e, portanto, legitimadora de discursos hegemônicos por serem os predominantemente considerados válidos e aceitos.

Cabe destacar que uma formação discursiva não se constitui como algo que se congela ou cristaliza por tempos indefinidos. Ela apresenta e determina uma regularidade própria de processos temporais e propicia a articulação de uma série de acontecimentos discursivos. Trata-se de uma correspondência entre diversas séries temporais que vão sendo produzidas (FOUCAULT, 1987), entretanto, não se constitui uma periodização totalitária em que,

[...] a partir de um certo momento e por um certo tempo, todo mundo pensaria da mesma forma, apesar das diferenças de superfície, diria a mesma coisa, através de um vocabulário polimorfo, e produziria uma espécie de grande discurso que se poderia percorrer indiferentemente em todos os sentidos. Ao contrário, a arqueologia descreve um nível de homogeneidade enunciativa que tem seu próprio recorte temporal, e que não traz com ela todas as outras formas de identidade e de diferenças que podem ser demarcadas na linguagem; e neste nível, ela estabelece um ordenamento, hierarquias e todo um florescimento que excluem uma sincronia maciça, amorfa, apresentada global e definitivamente (FOUCAULT, 1987, p. 169-170).

Assim, apesar de uma formação discursiva apresentar regularidades, destacamos que diferentes discursos convivem dentro de tal formação, compondo um arquivo, ou seja, um “[...] conjunto de discursos efetivamente pronunciados” (FOUCAULT, 1999, p. 272). Interessou-nos, então, nesta pesquisa, “[...] cartografar os enunciados discursivos que compõem os arquivos sobre pensamentospráticas e políticas curriculares buscando compor os arquivos desta discursividade” (CARVALHO, 2016, p. 8). 
Para tanto, foram utilizados todos os artigos produzidos nos quatro dossiês, no período descrito, buscando identificar - por meio da cartografia dos enunciados discursivos constituídos pelos conceitos, temáticas, abordagem teórico-epistemológica e metodológica, autores e conceitos referenciados - as regularidades, aproximações e distanciamentos.

\section{PERIÓDICO TEIAS: A PRODUÇÃO ACADÊMICA COMO FORMA DE RESISTÊNCIA NO CAMPO DA EDUCAÇÃO}

Ao longo do período entre 2013 a 2016, o periódico Teias editou quatro números em forma de dossiê organizado pela ABdC. Com relação à autoria dos editoriais e dos artigos e à filiação institucional dos autores, observamos a predominância de autores membros de instituições na Região Sudeste, seguida da Região Sul, Nordeste e Centro-Oeste do Brasil e uma em Portugal (Universidade do Minho), como pode ser observado a seguir:

Tabela 1. Quantitativo - editorial, artigos e instituições por ano de publicação

\begin{tabular}{c|c|c|c|c}
\hline Dossiês & $\mathbf{2 0 1 3}$ & $\mathbf{2 0 1 4}$ & $\mathbf{2 0 1 5}$ & $\mathbf{2 0 1 6}$ \\
\hline \multirow{2}{*}{ Editorial } & 2 & 1 & 1 & 1 \\
\cline { 2 - 5 } & UERJ/UNICAMP & UFRJ & UFBA & UFSC \\
\hline Artigos & 8 & 7 & 5 & 6 \\
\hline Autores & 13 & 11 & 7 & 9 \\
\hline Instituição & UFPA, UFPE, & UFRJ, UERJ, & UFRGS, & UFBA, UEPB, \\
& UFRJ, UNICAMP, & PUC/SP, & PUC/SP, & SEME/São \\
& UFS, UFMG, & UFPel, & UNEB, IFBA, & Paulo, UFP, \\
& PUC/SP, UFES, & UNESP, UFG, & UEPA, & UERJ, \\
& SEDU/Pernambuco, & SEME/Catalão & SEME/São & UFSCar \\
& PUC/SANTOS, & & Leopoldo & \\
& Universidade do & & & \\
& Minho & & & \\
& & & & \\
& & &
\end{tabular}

Sintetizando, em termos quantitativos, os dados relativos à região podem ser assim descritos (Gráfico 1): 


\section{Gráfico 1. Filiação institucional dos autores por região do Brasil e Portugal}

Conforme pode ser observado, as instituições situam-se, predominantemente, na Região Sudeste com a seguinte distribuição: São Paulo com oito instituições, Rio de Janeiro com quatro e Minas Gerais e Espírito Santo com uma instituição cada Estado. Sidone, Haddad e Mena-Chaco (2016, p. 17) já apontavam a concentração da produção científica no Estado de São Paulo:

No Brasil, também se verifica enorme heterogeneidade espacial das atividades de pesquisa científica, onde o padrão regional da distribuição das publicações e dos pesquisadores é altamente concentrado na região Sudeste, com destaque às capitais dos estados. Como exemplo, a cidade de São Paulo concentra cerca de $20 \%$ da produção científica brasileira e cresceu 21 posições na lista das cidades de maior geração de conhecimento no mundo durante a última década. Por conta disso, passou a figurar dentre os 20 municípios que mais produziram ciência no mundo (Royal Society, 2011), destacando-se internacionalmente entre as cidades que mais apresentaram crescimento na produção científica recentemente.

Em relação à entidade mantenedora das instituições às quais os autores estão filiados, temos a seguinte distribuição (Gráfico 2): 


\section{Gráfico 2. Filiação institucional dos autores por entidade mantenedora}

Podemos observar uma predominância de instituições de ensino federal, seguidas de instituições estaduais, localizadas, como já afirmado, na Região Sudeste, o que aponta para certa centralização do eixo de produção científica. Sidone, Haddad e Mena-Chaco (2016, p. 17) também destacam esse fenômeno ao mostrar que,

No caso brasileiro, a concentração espacial está diretamente relacionada à localização dos campi das universidades públicas, primordialmente as estaduais e federais, uma vez que essas são responsáveis pela maioria da atividade científica, padrão típico de países em desenvolvimento. Em 2009, somente sete universidades, localizadas nas regiões Sudeste e Sul do país, foram responsáveis por cerca de $60 \%$ dos trabalhos publicados em periódicos internacionais. Dentre elas, quatro possuem campi universitários localizados no Estado de São Paulo. Em 2009, a Universidade de São Paulo (USP) forneceu cerca de um quarto da produção brasileira seguida pela Universidade Estadual Paulista Júlio de Mesquita Filho (Unesp) e Universidade Estadual de Campinas (Unicamp) com cerca de 8,0\% [...].

Apresentamos abaixo (Quadro 2) uma discriminação detalhada da autoria por artigos e a procedência e/ou localização das universidades ou centros de pesquisa em que os autores atuam como estudantes, professores e pesquisadores, assim como os eixos temáticos de cada número do periódico e as temáticas dos artigos de cada revista: 
Quadro 2. Eixos e temáticas dos artigos por número, autores e filiação institucional

\begin{tabular}{|c|c|}
\hline VOLUME/ANO & $\begin{array}{l}\text { TEMÁTICA DOS ARTIGOS, AUTORES E FILIAÇÃO INSTITUCIONAL } \\
\text { (continua) }\end{array}$ \\
\hline \multirow[t]{9}{*}{ v. 14 n.33 (2013) } & a) CURRÍCULO, CONHECIMENTO E EXPERIÊNCIAS \\
\hline & $\begin{array}{c}\text { - AÇÃO PEDAGÓGICA DE PROFESSORES EM ESCOLAS RIBEIRINHAS } \\
\text { DA } \\
\text { c) } \quad \text { AMAZÔNIA } \\
\text { Acyr de Gerone Junior e Salomão Antonio Mufarrej Hage - UFPA }\end{array}$ \\
\hline & $\begin{array}{c}\text { - PERSPECTIVA PÓS-COLONIAL DAS RELAÇÕES ÉTNICO-RACIAIS } \\
\text { NAS } \\
\text { PRÁTICAS CURRICULARES: CONTEÚDOS SELECIONADOS E } \\
\boldsymbol{g}) \quad \text { SILENCIADOS } \\
\text { ele Guerreiro Ferreira - Secretaria Estadual de Educação de Pernambuco e Janssen } \\
\text { Felipe da Silva - UFPE. }\end{array}$ \\
\hline & $\begin{array}{l}\text { - CONHECIMENTO CIENTÍFICO E CURRÍCULO: ANOTAÇÕES SOBRE } \\
\text { UMA } \\
\text { i) ARTICULAÇÃO IMPOSSÍVEL E NECESSÁRIA } \\
\text { j) Carmen Teresa Gabriel - UFRJ }\end{array}$ \\
\hline & $\begin{array}{c}\text { OS SENTIDOS DO CONHECIMENTO PARA SUJEITOS EM } \\
\text { SITUAÇÃO DE } \\
\text { l) } \\
\text { m) } \quad \text { PRIVAÇÃO DE LIBERDADE } \\
\text { Cátia Alvisi e Dirce Zan - UNICAMP }\end{array}$ \\
\hline & $\begin{array}{l}\text { - CURRÍCULO DA ARQUITETURA DO LABORATÓRIO ESCOLAR DE } \\
\text { o) CIÊNCIAS E POSIÇÕES DE SUJEITO DEMANDADAS }\end{array}$ \\
\hline & $\begin{array}{l}\text { - MUDAR É DIFÍCIL MAS É NECESSÁRIO E URGENTE: UM NOVO } \\
\text { SENTIDO } \\
\text { r) }\end{array}$ \\
\hline & 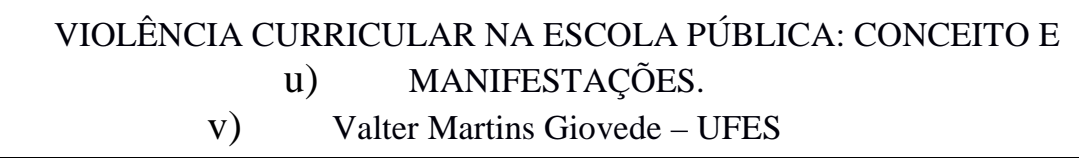 \\
\hline & $\begin{array}{l}\text { - O PROFESSOR COMO ARQUITETO DA PEDAGOG } \\
\text { UNIVERSIDADE } \\
\text { x) Flávia Vieira - Universidade do Minho, Portugal }\end{array}$ \\
\hline VOLUME/ANO & $\begin{array}{c}\text { TEMÁTICA DOS ARTIGOS, AUTORES E FILIAÇÃO } \\
\text { INSTITUCIONAL - } \\
\text { (Continuação) }\end{array}$ \\
\hline
\end{tabular}




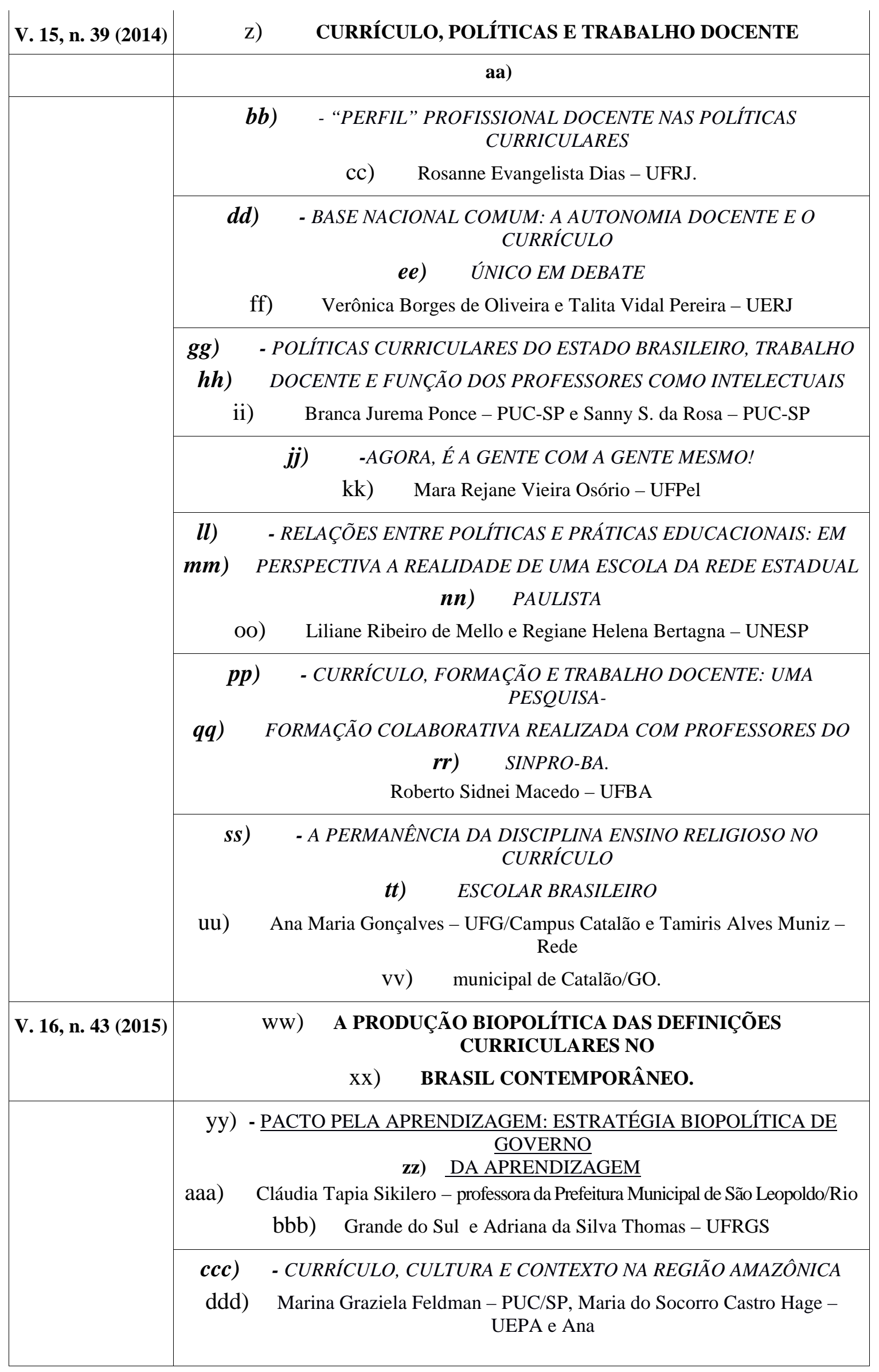




\begin{tabular}{|c|c|}
\hline & eee) Lúcia Nunes Pereira - UNEB \\
\hline & $\begin{array}{ll}\text { fff) } & \text { - O AMIGO, O CADERNO, O PENSAR } \\
\text { ggg) } & \text { Rosana Aparecida Fernandes - UFRGS }\end{array}$ \\
\hline & $\begin{array}{c}h h h) \\
\text { iii) TEMÁTICA DOS ARTIGOS, AUTORES E FILIAÇÃO } \\
\text { INSTITUCIONAL (Conclusão) }\end{array}$ \\
\hline & $\begin{array}{c}\text { jij) - BIOPOTENNCIAS CURRICULARES: RESISTENNCIAS EM CENÁRIOS } \\
\text { kkk) BIOPOLÍTICOS } \\
\text { lll) Igor Alexandre de Carvalho Santos - IFBA }\end{array}$ \\
\hline & $\begin{array}{c}\text { mmm) - INFLEXÕES SOBRE A VITALIDADE E O CUIDADO NA ÉPOCA } \\
\text { nnn) DO BIOPODER: A EMERGÊNCIA DO BIOCURRÍCULO } \\
\text { 00o) Leonardo Rangel dos Reis - IFBA, Campus Salvador }\end{array}$ \\
\hline V. 17, n. 47 (2016) & 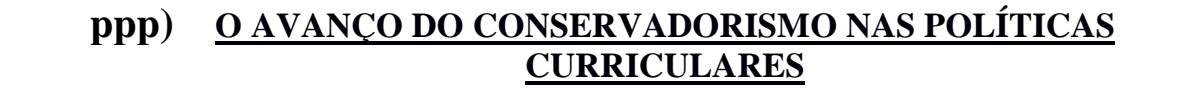 \\
\hline & $\begin{array}{c}\text { qqq) - OS SINOS DOBRAM POR NÓS: O MUNDO, O BRASIL E AS } \\
\text { NARRATIVAS }\end{array}$ \\
\hline & CURRICULARES DOS ÚLTIMOS TEMPOS \\
\hline & $\begin{array}{l}\text { Sss) Maria Inez Carvalho, Marcea Andrade Sales e Maria Roseli Gomes Brito - } \\
\text { UFBA }\end{array}$ \\
\hline & $\begin{array}{cl}\text { ttt) } & \text { - DEMOCRACIA QUE TEMOS/QUEREMOS, MEDIANTE O } \\
\text { uuu) } & \text { CONSERVADORISMO NAS POLÍTICAS EDUCACIONAIS }\end{array}$ \\
\hline & VVV) Francisca Pereira Salvino e Lenilda Cordeiro de Macedo - UEPB \\
\hline & $\begin{array}{cc}\text { www) } & \text { - A RELAÇÃO ENTRE O CURRÍCULO E AS AVALIAÇÕES EXTERNAS: } \\
& \text { UM } \\
& \boldsymbol{x} \boldsymbol{x} \boldsymbol{x}) \quad \text { ESTUDO SOBRE A REDE MUNICIPAL DE SÃO PAULO } \\
\text { yyy) } & \text { Isabela Bilecki da Cunha - Secretaria Municipal de Educação de São Paulo }\end{array}$ \\
\hline & $\begin{array}{l}\text { zzz) - O DISCURSO SOBRE GÊNERO NO CURRÍCULO DO MUNICÍPIO DE } \\
\text { aaaa) TERESINA: REINVENÇÃO DO CONSERVADORISMO? } \\
\text { bbbb) Neide Cavalcante Guedes - UFP }\end{array}$ \\
\hline & $\begin{array}{c}\text { cccc) - DISCURSOS CONSERVADORES NAS POLÍTICAS CURRICULARES: } \\
\text { DO } \\
\text { dddd) } \\
\text { SACERDÓCIO À PROFISSIONALIZAÇÃO DOCENTE } \\
\text { eeee) Verônica Borges de Oliveira - UERJ }\end{array}$ \\
\hline & $\begin{array}{c}\text { - A GESTÃO CURRICULAR LOCAL NAS MALHAS DAS REDES } \\
\text { POLÍTICAS } \\
\text { gggg) } \\
\text { EM ESCALA TRANSNACIONAL } \\
\text { hhhh) }\end{array}$ \\
\hline
\end{tabular}

Identificamos também as palavras-chave descritas pelos autores e acrescentamos outros conceitos que expressassem a ideia por eles trabalhada. Como havia conceitos inter-relacionados e 
que apareciam de forma muito pulverizada nos artigos, reunimos alguns. Por exemplo, no conceito currículo, agrupamos: currículo, currículos colonizados, violência curricular, currículo na concepção freiriana, política curricular, princípios curriculares e formativos, políticas educacionais de currículo, biocurrículo, narrativas curriculares e gestão curricular. No conceito formação de professores, agrupamos: professor, formação de professores, perfil profissional, profissionalização docente, autonomia docente, trabalho docente, subjetividade docente, profissionalização. Em práticas pedagógicas: ação pedagógica, autonomia pedagógica e reflexiva, práticas pedagógicas. Em educação freiriana, agrupamos: Paulo Freire, educação freiriana, educação popular, educação bancária, pedagogia libertadora. Apresentamos abaixo os conceitos mais recorrentes ${ }^{3}$ (Tabela 2):

Tabela 2. Frequência dos conceitos no período de 2013 a 2016

\begin{tabular}{l|c|c|c|c|c}
\hline \multicolumn{1}{c|}{ Conceitos } & $\mathbf{2 0 1 3}$ & $\mathbf{2 0 1 4}$ & $\mathbf{2 0 1 5}$ & $\mathbf{2 0 1 6}$ & Total \\
\hline Currículo & 11 & 7 & 3 & 7 & 28 \\
\hline Formação de professores & 2 & 9 & - & 1 & 12 \\
\hline Educação freiriana & 5 & - & - & - & 5 \\
\hline Práticas pedagógicas & 2 & 2 & - & - & 4 \\
\hline Educação & 2 & - & 2 & - & 4 \\
\hline Conhecimento científico & 3 & - & - & - & 3 \\
\hline Políticas públicas & - & 1 & 1 & 1 & 3 \\
\hline Escola pública & - & 1 & 1 & 1 & 3 \\
\hline Universidade & 2 & - & - & - & 2 \\
\hline Biopolítica & - & - & 2 & - & 2 \\
\hline Biopoder & - & & 2 & - & 2 \\
\hline Educação e Religião & - & 2 & - & - & 2 \\
\hline
\end{tabular}

O conceito currículo é o único que aparece em todas as edições, seguido de formação de professores, que não consta apenas em 2015 e que teve uma frequência maior em 2014, quando a temática se voltou para o debate sobre currículo, políticas e Trabalho Docente.

Os conceitos delimitados, de certa forma, têm uma relação com a abordagem teóricoepistemológica que fundamenta os artigos - Teoria Crítica e Pós-Crítica (tabela 3). Assumimos, neste trabalho, a perspectiva apontada por Lopes (2013, p. 9) ao se referir ao campo do currículo:

[...] a expressão teorias pós-críticas é utilizada para se referir às teorias que questionam os pressupostos das teorias críticas, marcadas pelas influências do marxismo, da Escola de Frankfurt e em alguma medida da fenomenologia, discussões em que as conexões entre currículo, poder e ideologia são destacadas.

\footnotetext{
${ }^{3}$ São indicados os conceitos que são apresentados acima de duas vezes.
} 
Lopes (2013, p. 10) defende a importância de compreender a expressão Teorias Pós-Críticas e o seu uso ao mostrar que,

[...] de uma expressão vaga e imprecisa que tenta dar conta de um conjunto de teorias que problematizam esse cenário pós-moderno: cenário de fluidas, irregulares e subjetivas paisagens, sejam elas étnicas, midiáticas, tecnológicas, financeiras ou ideológicas (Appadurai, 2001). Esse conjunto de teorias inclui os estudos pósestruturais, pós-coloniais, pós-modernos, pós-fundacionais e pós-marxistas.

Conforme a autora, não se trata de estabelecer um gradualismo, como se passássemos das Teorias Tradicionais para as Teorias Críticas de enfoque moderno e, posteriormente, para as Teorias Pós-Criticas. “Trata-se de operar com o hibridismo entre e nas correntes teóricas” (p.10). Esse hibridismo pode nos fazer "[...] compreender traços, sempre derridianamente suplementados, do passado no presente. Tal movimento também se associa à própria desconstrução dos limites espaçotemporais” (p. 10). Na tabela abaixo, podemos observar a coexistência dessas perspectivas.

Tabela 3. Abordagem teórico-epistemológica - 2013 a 2016

\begin{tabular}{l|c|c|c|c|c}
\hline Abordagem teórico-epistemológica & $\mathbf{2 0 1 3}$ & $\mathbf{2 0 1 4}$ & $\mathbf{2 0 1 5}$ & $\mathbf{2 0 1 6}$ & Quantidade $^{\mathbf{4}}$ \\
\hline Teoria Crítica $^{5}$ & 3 & 4 & 1 & 5 & 13 \\
\hline Teoria Pós-Crítica $^{6}$ & 6 & 6 & 5 & 4 & 21 \\
\hline
\end{tabular}

A definição, quanto às abordagens, aparece colocada de forma explícita pelos autores ou foi estabelecida após análise da discursividade exposta nos artigos. É interessante observar que as abordagens denominadas Teoria Crítica e Pós-Crítica se mantêm nos quatro dossiês, havendo certa prevalência da segunda sobre a primeira, com destaque para o ano de 2015, possivelmente, por causa do eixo temático do dossiê que foi A produção biopolítica das definições curriculares no Brasil contemporâneo.

O movimento que pudemos observar do entrelaçamento de diferentes abordagens teóricoepistemológicas sugere que o prefixo “pós” se refere

[...] ao abandono dos axiomas essencialistas [...]. Ser 'pós' algum movimento ou escola de pensamento [...] implica problematizar esse mesmo movimento ou escola de pensamento, questionar as suas bases, as suas condições de possibilidade e de

\footnotetext{
${ }^{4}$ A quantidade expressa supera o número de artigos pelo fato de alguns autores assumirem diferentes perspectivas descritas nas notas seguintes.

${ }^{5}$ Foram agrupadas perspectivas que se aproximam teoricamente, incluindo nesta denominação a perspectiva sóciohistórica e estudos de gênero na perspectiva crítica.

${ }^{6}$ Foram agrupados nessa abordagem trabalhos fundamentados nas perspectivas teóricas denominadas PósEstruturalista, Pós-Fundacionalista, estudos com os cotidianos, filosofia da diferença e desconstrucionismo.
} 
impossibilidade. Não é um avanço linear, não é uma evolução ou uma superação a supor que os traços do movimento ou da escola de pensamento questionados são apagados (LOPES, 2013, p. 11).

Não se trata, pois, de uma descrição epistemológica, mas de uma análise arqueológica que [...] individualiza e descreve formações discursivas, isto é, deve compará-las, opô-las umas às outras na simultaneidade em que se apresentam, distingui-las das que não têm o mesmo calendário, relacioná-las no que podem ter de específico com as práticas não discursivas que as envolvem e lhes servem de elemento geral [...]. O estudo arqueológico está sempre no plural: ele se exerce em uma multiplicidade de registros; percorre interstícios e desvios (FOUCAULT, 1987, p. 180).

Continuando, o autor afirma que a análise arqueológica é uma análise comparativa “[...] que não se destina a reduzir a diversidade dos discursos nem delinear a unidade que deve totalizá-los, mas sim a repartir a diversidade em figuras diferentes. A comparação arqueológica não tem um efeito unificador, mas multiplicador” (FOUCAULT, 1987, p. 183). Com isso posto, queremos afirmar que as aproximações realizadas entre diferentes perspectivas epistemológicas foram feitas no sentido de observar os movimentos de volta, ruptura, ressignificações, descontruções, reconstruções operados pelos autores, o que mostra que estamos distante de um pensamento único no campo de produção das pesquisas em educação.

A abordagem metodológica que, por sua vez, também se relaciona com os conceitos e com a abordagem teórica, pode ser assim expressa (Tabela 4):

Tabela 4. Abordagem metodológica - 2013 a $2016^{7}$

\begin{tabular}{l|c|c|c|c|c}
\hline Abordagem metodológica & $\mathbf{2 0 1 3}$ & $\mathbf{2 0 1 4}$ & $\mathbf{2 0 1 5}$ & $\mathbf{2 0 1}$ & Quant \\
\hline Ensaio & 2 & 1 & 3 & 1 & 7 \\
\hline Pesquisa documental & 1 & 3 & - & 2 & 6 \\
\hline Teoria do discurso pós-fundacional e pós-estrutural & 1 & 2 & 1 & 2 & 6 \\
\hline Pesquisa bibliográfica & 1 & - & 1 & 1 & 3 \\
\hline Pesquisa qualitativa (entrevista, de campo) & 1 & 1 & 1 & - & 3 \\
\hline Pesquisa participante & 1 & - & - & 1 & 2 \\
\hline Etnopesquisa-formação colaborativa & & 1 & - & - & 1 \\
\hline Pesquisa etnográfica & 1 & - & - & - & 1 \\
\hline
\end{tabular}

\footnotetext{
${ }^{7}$ Conforme nomeado pelos autores. Não havendo referência à metodologia, o trabalho foi denominado ensaio. A quantidade expressa supera o número de artigos pelo fato de alguns autores assumirem mais de uma abordagem metodológica.
} 
A abordagem metodológica de maior incidência é o ensaio. Em 2015, foi uma das estratégias mais utilizadas possivelmente pela temática do dossiê. Como o ensaio é uma abordagem de natureza reflexiva, interpretativa e problematizadora, distancia-se das abordagens classificatórias, objetivistas da ciência e dialoga com teorias epistemológicas de cunho pós-críticas. Lopes (2013, p.17), referindo-se às teorias pós-críticas, mostra-nos que elas

[...] são marcadamente anti-essencialistas, anti-objetivistas, críticos dos determinismos e valorizam a linguagem como central na mediação da compreensão do social, substituindo as estruturas pelo discurso e ampliando as discussões filosóficas da cultura.

A pesquisa documental também foi, especificamente, utilizada em seis artigos. A predominância é de análise de documentos regionais, como os da Secretaria Municipal de Educação da Amazônia e Estadual de São Paulo, com dados relativos ao sistema de avaliação de São Paulo, registros de escola, como Projeto Político-Pedagógico, Plano de Ensino, Regimento e outros. Em nível federal, encontramos dados no Índice de Desenvolvimento da Educação Básica, na Constituição Federal de 1988, na Lei de Diretrizes e Bases da Educação Nacional, nº 9.394/1996, e em documentos relativos ao ensino religioso, como resoluções e pareceres.

Apesar de não haver menção à análise documental, muitos autores utilizaram documentos legais e normativos federais como referências para subsidiar seus artigos, conforme pode ser observado na Tabela 4. Isso aponta a força das políticas instituídas nas produções acadêmicas no campo educacional ou a necessidade de compreensão dessas políticas como forma de resistência ao que está sendo implementado na conjuntura atual, o que fica bastante evidenciado nos três últimos dossiês publicados.

A Teoria do Discurso foi também uma abordagem metodológica bastante utilizada. As referências teóricas que se destacam nessa perspectiva são Foucault, Laclau e Mouffe. Na maioria dos casos em que houve a pesquisa documental, os autores fizeram uso dessa perspectiva teórica para tecer um quadro de compreensão sobre os documentos.

Podemos observar que a escolha das abordagens metodológicas esteve estritamente associada à referência teórico-epistemológica. Essa relação fica clara se comparamos os dados relativos à metodologia com os dados da Tabela 3 com a Tabela 4. Dos 13 trabalhos relacionados com a Teoria Crítica, dez fizeram o uso de abordagens de cunho qualitativo com autores que afirmaram ter realizado entrevista, pesquisa de campo, observação participante, etnopesquisaformação colaborativa e pesquisa etnográfica e bibliográfica. Por outro lado, o grupo de 21 autores que fundamentou seus trabalhos na abordagem considerada como Teorias Pós-Críticas utilizou, 
como metodologia, a análise da discursividade, existe, pois, uma correspondência entre as perspectivas epistemológicas e metodológicas.

\section{PERSONAGENS E CONCEITOS CONSTITUIDORES DA DISCURSIVIDADE EXPRESSA NOS DOSSIÊS}

Em relação aos autores referenciados, consideramos os que tiveram, no mínimo, cinco obras citadas entre livros e artigos. No Quadro 3, observamos que Freire apresenta o maior número de obras referenciadas - onze, uma em coautoria -, sendo Pedagogia da autonomia: saberes necessários à prática educativa a mais citada, seguida de Pedagogia do oprimido. Dentre os autores estrangeiros, Foucault se descaca com 15 obras referenciadas. O livro História da sexualidade I: a vontade de saber é o mais citado. Deleuze também teve destaque significativo com 11 obras citadas, sendo três em coautoria.

\section{Quadro 3. Autores $^{8}$ referenciados em artigos e livros e número de citação}

\begin{tabular}{|c|c|c|c|c|c|}
\hline \multirow[t]{2}{*}{ Autor } & \multirow{2}{*}{ Obra } & \multicolumn{2}{|c|}{ Artigo } & \multirow[t]{2}{*}{ Livro } & \multirow{2}{*}{$\begin{array}{c}\mathrm{N}^{\mathrm{o}} \text { de } \\
\text { Citação } \\
\text { (continua) }\end{array}$} \\
\hline & & $\mathrm{L}$ & $\mathrm{P}$ & & \\
\hline \multirow[t]{10}{*}{ FREIRE, P. } & $\begin{array}{c}\text { Pedagogia da autonomia: saberes } \\
\text { necessários à prática educativa }\end{array}$ & & & $\mathrm{x}$ & 5 \\
\hline & Pedagogia do oprimido & & & $\mathrm{x}$ & 4 \\
\hline & $\begin{array}{c}\text { Professora sim, tia não: cartas a quem ousa } \\
\text { ensinar }\end{array}$ & & & $\mathrm{x}$ & 2 \\
\hline & A educação na cidade & & & $\mathrm{x}$ & 2 \\
\hline & $\begin{array}{c}\text { Criando métodos de pesquisa alternativa: } \\
\text { aprendendo a fazê-la melhor através da } \\
\text { ação }\end{array}$ & $\mathrm{x}$ & & & 1 \\
\hline & $\begin{array}{l}\text { A importância do ato de ler: em três artigos } \\
\text { que se completam }\end{array}$ & & & $\mathrm{x}$ & 1 \\
\hline & Educação e mudança & & & $\mathrm{x}$ & 1 \\
\hline & $\begin{array}{c}\text { Pedagogia da esperança: um reencontro } \\
\text { com a Pedagogia do oprimido }\end{array}$ & & & $\mathrm{x}$ & 1 \\
\hline & Política e educação & & & $\mathrm{x}$ & 1 \\
\hline & $\begin{array}{l}\text { Pedagogia da indignação: cartas } \\
\text { pedagógicas e outros escritos }\end{array}$ & & & $\mathrm{x}$ & 1 \\
\hline
\end{tabular}

\footnotetext{
${ }^{8}$ Foram incluídos nesse quadro os autores que tiveram acima de cinco obras citadas entre artigos e livros (inclusive em coautoria).
} 


\begin{tabular}{|c|c|c|c|c|c|}
\hline Autor & Obra & Artigo & Livro & $\begin{array}{c}\mathrm{N}^{\mathrm{o}} \mathrm{de} \\
\text { citação }\end{array}$ & $\begin{array}{c}\text { Autor } \\
\text { (continuação) }\end{array}$ \\
\hline $\begin{array}{l}\text { FREIRE, P.; } \\
\text { SHOR, I. }\end{array}$ & Medo e ousadia: o cotidiano do professor. & & & $\mathrm{x}$ & 1 \\
\hline \multirow[t]{5}{*}{ LOPES, A. C. } & $\begin{array}{c}\text { Políticas curriculares: continuidade ou } \\
\text { mudança de rumos? }\end{array}$ & & $\mathrm{x}$ & & 1 \\
\hline & $\begin{array}{l}\text { Política de currículo: recontextualização } \\
\text { por hibridismo }\end{array}$ & & $\mathrm{x}$ & & 1 \\
\hline & Discursos nas políticas de currículo & & & $\mathrm{x}$ & 1 \\
\hline & Ainda é possível um currículo político? & $\mathrm{x}$ & & & 1 \\
\hline & Democracia nas políticas de currículo & & & & 1 \\
\hline $\begin{array}{c}\text { LOPES, A. C.; } \\
\text { MENDONÇA, D. }\end{array}$ & A teoria do discurso de Ernesto Laclau & & $\mathrm{x}$ & $\mathrm{x}$ & 1 \\
\hline $\begin{array}{l}\text { LOPES, A. C.; } \\
\text { MACEDO, E.; } \\
\text { TURA, M. de L. }\end{array}$ & $\begin{array}{l}\text { As representações sociais e os estudos de } \\
\text { política de currículo para formação docente }\end{array}$ & & $\mathrm{x}$ & & 1 \\
\hline $\begin{array}{l}\text { LOPES, A.C.; } \\
\text { COSTA, H. }\end{array}$ & $\begin{array}{l}\text { Da recontextualização à tradução: } \\
\text { investigando políticas de currículo }\end{array}$ & & $\mathrm{x}$ & & 1 \\
\hline $\begin{array}{l}\text { LOPES, A.C.; } \\
\text { DIAS, R.E. }\end{array}$ & $\begin{array}{c}\text { Competências na formação de professores } \\
\text { no Brasil: o que (não) há de novo }\end{array}$ & & $\mathrm{x}$ & & 1 \\
\hline $\begin{array}{l}\text { LOPES, A.C.; } \\
\text { BORGES, V. }\end{array}$ & Formação docente, um projeto impossível & & $\mathrm{x}$ & & 1 \\
\hline $\begin{array}{l}\text { LOPES, A. C.; } \\
\text { MACEDO, E.; } \\
\text { TURA, M. de L. }\end{array}$ & $\begin{array}{l}\text { As representações sociais e os estudos de } \\
\text { política de currículo para formação docente }\end{array}$ & & $\mathrm{x}$ & & 1 \\
\hline $\begin{array}{l}\text { LOPES, A.C.; } \\
\text { MACEDO, E. }\end{array}$ & Teorias de currículo & & & $\mathrm{x}$ & 2 \\
\hline \multirow[t]{6}{*}{ VEIGA-NETO, A. } & Governamento e governamentalidade & & $\mathrm{x}$ & & 2 \\
\hline & Foucault \& a educação & & & $\mathrm{x}$ & 2 \\
\hline & Obra & Artigo & Livro & $\begin{array}{c}\mathrm{N}^{\circ} \text { de } \\
\text { citação }\end{array}$ & $\begin{array}{c}\text { Autor } \\
\text { (continuação) }\end{array}$ \\
\hline & Cultura e currículo & & $\mathrm{x}$ & & 2 \\
\hline & $\begin{array}{l}\text { Crise da modernidade e inovações } \\
\text { curriculares: da disciplina para o controle }\end{array}$ & & $\mathrm{x}$ & & 1 \\
\hline & Currículo, cultura e sociedade & & $\mathrm{x}$ & & 1 \\
\hline
\end{tabular}




\begin{tabular}{|c|c|c|c|c|c|}
\hline \multirow[t]{2}{*}{$\begin{array}{l}\text { VEIGA-NETO, A; } \\
\text { LOPES, M. C. }\end{array}$} & Inclusão e governamentalidade & & $\mathrm{x}$ & & 1 \\
\hline & $\begin{array}{c}\text { Para pensar de outros modos a } \\
\text { modernidade pedagógica }\end{array}$ & & $\mathrm{x}$ & & 1 \\
\hline \multirow[t]{15}{*}{ FOUCAULT, $\mathrm{M}}$. & $\begin{array}{l}\text { Historia da sexualidade I: a vontade de } \\
\text { saber }\end{array}$ & & & $\mathrm{x}$ & 6 \\
\hline & O sujeito e o poder & $\mathrm{x}$ & & & 2 \\
\hline & Segurança, território, população & & & $\mathrm{x}$ & 1 \\
\hline & Nascimento da biopolitica & & & $\mathrm{x}$ & 2 \\
\hline & $\begin{array}{l}\text { Omnes et singulatim: uma crítica da razão } \\
\text { política }\end{array}$ & & & & 1 \\
\hline & A arqueologia do saber & & & $\mathrm{x}$ & 2 \\
\hline & $\begin{array}{l}\text { Sobre a genealogia da ética: uma revisão do } \\
\text { trabalho }\end{array}$ & & & & 1 \\
\hline & Microfísica do poder & & & $\mathrm{x}$ & 1 \\
\hline & Em defesa da sociedade & & & $\mathrm{x}$ & 1 \\
\hline & Vigiar e punir & & & $\mathrm{x}$ & 2 \\
\hline & Verdade e poder & & & $\mathrm{x}$ & 1 \\
\hline & Poder e saber & & & $\mathrm{x}$ & 1 \\
\hline & $\begin{array}{l}\text { As palavras e as coisas: uma arqueologia } \\
\text { das ciências humanas }\end{array}$ & & & $\mathrm{x}$ & 1 \\
\hline & Verdade e subjetividade & & & $\mathrm{x}$ & 1 \\
\hline & As técnicas de s & & & & 1 \\
\hline Autor & Obra & Artigo & Livro & $\begin{array}{l}\mathbf{N}^{0} \text { de } \\
\text { citação }\end{array}$ & $\begin{array}{c}\text { Autor } \\
\text { (continuação) }\end{array}$ \\
\hline \multirow[t]{8}{*}{ DELEUZE, G. } & Conversações & & & $\mathrm{x}$ & 3 \\
\hline & L’ île deserte et autres textes & & & $\mathrm{x}$ & 1 \\
\hline & A imagem-tempo & & & $\mathrm{x}$ & 1 \\
\hline & A imagem-movimento & & & $\mathrm{x}$ & 1 \\
\hline & Francis Bacon: lógica da sensação & & & $\mathrm{x}$ & 1 \\
\hline & Diferença e repetição & & & $\mathrm{x}$ & 1 \\
\hline & Bergsonismo & & & $\mathrm{x}$ & 1 \\
\hline & A ilha deserta: e outros textos & & & $\mathrm{x}$ & 1 \\
\hline \multirow{3}{*}{$\begin{array}{l}\text { DELEUZE, G.; } \\
\text { GUATTARI, F. }\end{array}$} & O que é filosofia? & & & $\mathrm{x}$ & 2 \\
\hline & Mil platôs: capitalismo e esquizofrenia & & & $\mathrm{x}$ & 3 \\
\hline & O Anti-Édipo: capitalismo e esquizofrenia & & & $\mathrm{x}$ & 1 \\
\hline \multirow[t]{3}{*}{ BAUMAN, Z. } & Globalização: as consequências humanas & & & $\mathrm{x}$ & 3 \\
\hline & Modernidade líquida & & & $\mathrm{x}$ & 1 \\
\hline & $\begin{array}{l}\text { Os desafios da educação: aprender a } \\
\text { caminhar sobre areias movediças }\end{array}$ & & & $\mathrm{x}$ & 1 \\
\hline
\end{tabular}




\begin{tabular}{|c|c|c|c|c|c|}
\hline & $\begin{array}{l}\text { "Estamos constantemente correndo atrás. O } \\
\text { que ninguém sabe é correndo atrás de quê" }\end{array}$ & & $\mathrm{x}$ & & 1 \\
\hline & 44 cartas do mundo líquido moderno & & & $\mathrm{x}$ & 1 \\
\hline & $\begin{array}{l}\text { A sociedade individualizada: vidas } \\
\text { contadas e histórias vividas }\end{array}$ & & & $\mathrm{x}$ & 1 \\
\hline \multirow[t]{4}{*}{ LACLAU, E. } & Emancipación y diferencia & & & $\mathrm{x}$ & 5 \\
\hline & $\begin{array}{l}\text { Nuevas reflexiones sobre la revolución de } \\
\text { nuestro tempo }\end{array}$ & & & $\mathrm{x}$ & 1 \\
\hline & Política de la retórica & & & & 1 \\
\hline & New reflectionson there volutiono four time & & & $\mathrm{x}$ & 1 \\
\hline \multirow[t]{2}{*}{$\begin{array}{l}\text { LACLAU, E.; } \\
\text { MOUFFE, C. }\end{array}$} & $\begin{array}{c}\text { Hegemonía y estratégia socialista: hacia } \\
\text { una radicalización de la democracia }\end{array}$ & & & $\mathrm{x}$ & 4 \\
\hline & La razón populista & & & $\mathrm{x}$ & 1 \\
\hline Autor & Obra & Artigo & Livro & $\begin{array}{l}\mathbf{N}^{0} \text { de } \\
\text { citação }\end{array}$ & $\begin{array}{c}\text { Autor } \\
\text { (conclusão) }\end{array}$ \\
\hline \multirow[t]{2}{*}{ MOUFFE, C. } & O regresso do político & & & $\mathrm{x}$ & 1 \\
\hline & Por um modelo agonístico de democracia & & $\mathrm{x}$ & & 1 \\
\hline \multirow[t]{6}{*}{ BALL, S. J. } & $\begin{array}{c}\text { Education reforma critical and post- } \\
\text { structural approach }\end{array}$ & & & $\mathrm{x}$ & 1 \\
\hline & $\begin{array}{c}\text { Cidadania global, consumo e política } \\
\text { educacional }\end{array}$ & $\mathrm{x}$ & & & 1 \\
\hline & $\begin{array}{l}\text { The teacher's soul and the terrors of } \\
\text { performativity }\end{array}$ & & $\mathrm{x}$ & & 1 \\
\hline & $\begin{array}{c}\text { Performatividade, privatização e o pós- } \\
\text { Estado do bem-estar }\end{array}$ & & $\mathrm{x}$ & & 1 \\
\hline & The education debate & & & $\mathrm{x}$ & 1 \\
\hline & $\begin{array}{c}\text { Global educationInc. new policy networks } \\
\text { and the neo-liberal imaginary }\end{array}$ & & & $\mathrm{x}$ & 1 \\
\hline $\begin{array}{l}\text { BALL, S. J.; } \\
\text { BOWE, R. }\end{array}$ & $\begin{array}{c}\text { El currículum nacional y su “puesta em } \\
\text { práctica”: El papel de los departamentos de } \\
\text { materias o asignaturas }\end{array}$ & & $\mathrm{x}$ & & 1 \\
\hline
\end{tabular}

Como afirmado, Freire está na condição de autor mais referenciado entre os brasileiros. Carvalho (2011), analisando o discurso do periódico Transnacional Curriculum Inquiry (TCI), também destaca Freire como único autor brasileiro citado nas publicações no período de 2004 até 2009 nesse periódico. Chama a atenção, ainda, entre os autores nacionais, Lopes que, entre obras de autoria própria mais a produção conjunta com outros autores, soma um total de doze trabalhos. 
Veiga Neto também se destaca com cinco obras próprias, mais duas em coautoria. A tabela a seguir demonstra esses números:

Tabela 5. Autores referenciados, número de obras e citações ${ }^{9}$

\begin{tabular}{|c|c|c|c|c|}
\hline Autores - & Artigo & Livro & $\begin{array}{l}\mathrm{N}^{\mathrm{o}} \text { de } \\
\text { obras }\end{array}$ & $\begin{array}{l}\mathbf{N}^{\mathbf{0}} \\
\text { citaçã } \\
0\end{array}$ \\
\hline \multicolumn{5}{|l|}{ Brasileiros } \\
\hline FREIRE, P. & 1 & 11 & 12 & 22 \\
\hline VEIGA-NETO, A. & 4 & 1 & 5 & 8 \\
\hline LOPES, A. C. et al. & 5 & 2 & 8 & 8 \\
\hline LOPES, Alice C. & 4 & 1 & 5 & 5 \\
\hline MACEDO, R. & - & 4 & 4 & 4 \\
\hline VEIGA-NETO, A; LOPES, M. C. & 2 & - & 2 & 2 \\
\hline MACEDO, R. S. & - & 4 & 4 & 4 \\
\hline OLIVEIRA, I. A. & 4 & - & 4 & 4 \\
\hline MACEDO, E. & 3 & - & 3 & 3 \\
\hline DALE, R. & 3 & - & 3 & 3 \\
\hline ROSE, N. & 3 & - & 3 & 3 \\
\hline ROSA, S. S. & 3 & - & 3 & 3 \\
\hline SAVIANI, D. & - & 2 & 2 & 2 \\
\hline FREITAS, L. C. & 1 & 1 & 2 & 2 \\
\hline CORTELLA, M. S. & 2 & - & 2 & 2 \\
\hline DIAS, R. E. & 1 & 1 & 2 & 2 \\
\hline DIAS, R. E. et al. & 2 & - & 2 & 2 \\
\hline SAUL, A. M. & 2 & - & 2 & 2 \\
\hline CUNHA, L. A. & 2 & - & 2 & 2 \\
\hline VATTIMO, G. & 2 & - & 2 & 2 \\
\hline BROOKE, N.; CUNHA, M. A. & 2 & - & 2 & 2 \\
\hline CALDAS, A. N. & - & 2 & 2 & 2 \\
\hline BOING, L.; LUDKE, M. & 1 & 1 & 2 & 2 \\
\hline SILVA, J. F. et al. & 2 & & 2 & 2 \\
\hline VATTIMO, G. & 2 & - & 2 & 2 \\
\hline LOCKMANN, K. et al. & 1 & - & 1 & 2 \\
\hline BONAMINO, A. et al & 2 & - & 2 & 2 \\
\hline GABRIEL, C. T. & 2 & & 2 & 2 \\
\hline PEREIRA, T. V. & 1 & 1 & 2 & 2 \\
\hline
\end{tabular}

Documentos

Autores -

\begin{tabular}{l|l|l|l|} 
Artigo & Livro & $\mathbf{N}^{\circ}$ de & $\mathbf{N}^{\circ}$ citação \\
\hline
\end{tabular}

\footnotetext{
${ }^{9}$ Foram considerados os autores citados mais de duas vezes.
} 


\begin{tabular}{|c|c|c|c|c|}
\hline & & & obras & Conclusão \\
\hline BRASIL & \multicolumn{3}{|c|}{18 documentos } & 21 \\
\hline ANFOPE & \multicolumn{3}{|c|}{2 documentos } & 2 \\
\hline \multicolumn{5}{|c|}{ Autores estrangeiros } \\
\hline FOUCAULT, $\mathrm{M}$. & 3 & 7 & 15 & 24 \\
\hline DELEUZE, G. & & 9 & 9 & 18 \\
\hline LACLAU, E. & 1 & 3 & 4 & 8 \\
\hline BAUMAN, Z. & 2 & 5 & 7 & 8 \\
\hline BALL, S. J. & 3 & 3 & 6 & 6 \\
\hline DELEUZE, G.; GUATTARI, F. & - & 3 & 3 & 5 \\
\hline LACLAU, E.; MOUFFE, C. & & 2 & 2 & 5 \\
\hline GOODSON, I. & 1 & 2 & 1 & 3 \\
\hline ARENDT, $\mathrm{H}$. & - & 3 & 3 & 3 \\
\hline BALL, S. J.; BOWE, R. & 2 & - & 2 & 2 \\
\hline NÓVOA, A. & & 2 & 2 & 2 \\
\hline MOUFFE, C. & 1 & 1 & 2 & 2 \\
\hline APPLE, M. W. & 1 & 1 & 2 & 2 \\
\hline MIGNOLO, W. & Conferência & 1 & 2 & 2 \\
\hline DERRIDA, J. & - & 2 & 2 & 2 \\
\hline FORQUIN, J. C. & 1 & 1 & 2 & 2 \\
\hline
\end{tabular}

Vale destacar as citações nos artigos referentes aos ordenamentos legais e normativos produzidos pelo Ministério da Educação, o que denota, de certa forma, a centralidade das políticas no discurso sobre educação, currículo e formação de professores nos dossiês. Dentre os documentos mais citados, destacam-se a Lei de Diretrizes e Bases da Educação Nacional, $n^{\circ}$ 9.394/96; a Constituição Federal de 1988; o Parecer $\mathrm{n}^{0}$ 3/2004, que dispõe sobre as diretrizes curriculares nacionais para a educação das relações étnico-raciais e para o ensino de História e cultura afrobrasileira e africana; o Plano Nacional de Educação; a Resolução n ${ }^{0}$ 1/2006, que institui as diretrizes curriculares nacionais para o Curso de Graduação em Pedagogia, licenciatura; a Resolução $\mathrm{CNE} / \mathrm{CEB} \mathrm{n}^{\circ} 7 / 2010$, que institui as diretrizes curriculares nacionais do ensino fundamental de nove anos; as versões da Base Nacional Comum Curricular, entre outros.

A questão do currículo único e autonomia docente no debate da Base Nacional Comum Curricular é um tema recorrente, bem como as políticas de formação docente e as avaliações em larga escala. Essas questões são problematizadas tanto a partir das Teorias Críticas, quanto das Teorias Pós-Críticas, com ênfase em autores como Foucault e Deleuze.

Para identificar os conceitos tomados dos autores mais referenciados, que são Freire e Foucault, buscamos os artigos em que eles foram citados. Das teorizações propostas por Freire, observamos apropriações por parte dos autores sobre as reflexões em torno da fenomenologia, 
principalmente no que se refere ao rompimento com o empirismo e o racionalismo que separam o indivíduo do mundo. Essas reflexões do campo da fenomenologia bem como da dialética são utilizadas na problematização do conceito de educação e do conceito de educação bancária, com vistas a discutir a lógica eurocêntrica, em que a diferença cultural é eliminada da reflexão epistemológica e da produção do conhecimento sistematizado na escola por meio de práticas que garantam saberes que são depositados no outro, colonizando-o, subalternizando-o, oprimindo-o (GEROME JR; HAGE, 2013); (FERREIRA, 2013) e (SAUL, A. M.; SAUL, A., 2013).

Uma experiência na Rede Pública Municipal de Igarapé-Mirim (Amazônia) foi analisada, pelo fato de o município, no período entre 2009 e 2012, ter sido administrado por um governo de caráter popular, petista, que implantou, durante sua gestão, um projeto pedagógico denominado Escola Açaí, alicerçado na pedagogia freiriana de educação. Gerome Júnior e Hage (2013) buscam, assim, a presença dessa pedagogia no discurso dos professores e identificam, entre outras, várias premissas, como: autonomia docente; consciência; compromisso com o outro; educação libertadora; construção de uma educação progressista e revolucionária, que liberta o educador e o educando; formação de um sujeito livre; sala de aula como espaço de produção e não lugar apenas para se transferir conhecimento; ação pedagógica dos professores, que envolve o conhecimento do contexto histórico-cultural e social dos alunos, por meio da dialogicidade, entre outras.

Saul e Saul (2013) buscam apresentar um quadro conceitual inspirado na matriz de pensamento de Paulo Freire para estimular e subsidiar as equipes escolares na atribuição de um novo significado ao Projeto Político-Pedagógico das escolas e ao processo de sua elaboração. O pensamento freiriano é, assim, um referencial utilizado na tessitura de uma nova compreensão desse Projeto. Os autores defendem ainda a opção de uma educação a favor da emancipação do ser humano e de uma escola na qual se trabalhe tendo em vista a construção de um conhecimento crítico-libertador.

Ainda com base em Freire, Giovedi (2013) propõe uma reflexão sobre currículo em uma perspectiva crítico-libertadora, como forma de resistência e de superação da violência curricular, ou seja, utiliza-se do pensamento freiriano para discutir currículo e fazer uma reflexão sobre a escola e a violência, especificamente, a violência curricular.

Na mesma linha de reflexão sobre currículo nessa perspectiva, outro trabalho discute a concepção de diversidade cultural assentada no princípio pedagógico do acolhimento à heterogeneidade, o que significa reconhecer o outro como sujeito de sua história e considera que a 
prática docente, embasada na tríade currículo, cultura e contexto, é fundamental para ampliar o debate na perspectiva de se viver uma educação emancipatória (FERREIRA; SILVA, 2013).

Como já foi mencionado, Foucault, entre os estrangeiros, é o que se destaca tendo maior número de obras citadas e os conceitos de governamentalidade e biopoder são os mais referenciados. Entre as publicações que a ele se referem, destacamos um artigo que traz o conceito de governamentalidade como fundamento teórico/metodológico/analítico nos estudos sobre a formação de professores de Matemática na Universidade Aberta do Brasil (OSÓRIO, 2014).

Sikilero e Thomas (2015) analisam a política denominada Pacto pela Aprendizagem na Idade Certa. Utiliza-se das várias obras de Foucault em que o autor analisa os conceitos de poder, governamentalidade, governamentação, biopoder, biopolítica, entre outros. Essa política é apontada como uma forma de gestão da população e de seu corpo, dando ênfase à estatística como tecnologia imprescindível aos modos de conduzir a população, ou seja, é uma política que coloca em funcionamento estratégias que estão em consonância com programas e projetos governamentais voltados para a aprendizagem e para o investimento do/no sujeito como aprendente, de forma que ele possa participar do jogo do mercado do neoliberalismo.

Reis (2015) discute o conceito de biopolítica e as formas de governo do século XX que se voltavam para a docilização do corpo - as sociedades disciplinares - e discute o conceito de currículo como artefato educacional nas sociedades de controle na atualidade. Aponta as relações entre os currículos em contextos biopolíticos, em que busca uma formação pautada no empreendedorismo, na competência e na qualidade. Entretanto, o autor nos alenta para o fato de que há um grupo de teóricos, em sua maioria de autoria italiana, entre os quais se destacam Agamben, Lazzarato e Negri, que desdobraram as potencialidades do conceito de biopolítica, com base na leitura que Deleuze fez da obra de Foucault. A partir desses autores, o conceito de biopolítica recebe uma guinada que lhe dá uma capacidade de insubordinação. O autor introduz, assim, outro conceito, que é o de biopotências curriculares como uma forma de acreditar no mundo e de resistir às políticas em curso na atualidade.

A discussão sobre a educação na contemporaneidade, implicada com os processos vitais, é apontada como uma espécie de potencial vetor de mais-vida. As relações entre conhecimento, educação e controle da vida e dos corpos, novos sentidos nas sociedades do cuidado e a emergência do biocurrículo, ou seja, do corpo sendo tomado como questão política e curricular, também são problematizados (SANTOS, 2015). 
Como afirmamos ao longo do artigo, há, na discursividade manifesta nos dossiês, uma mescla e/ou oscilação das premissas relacionadas com as Teorias Críticas e Pós-Críticas. Assim, os conceitos tomados dos autores referenciados nos trabalhos apontam, por um lado, para a ideia da educação como possibilidade de intervenção, transformação social, emancipação e formação de sujeitos críticos e autonômos. Por outro, a educação está associada a sentidos, como biopolítica, controle dos corpos e da conduta, cuidado de si e dos outros, entre outros. Essas perspectivas diferenciadas incidem nos quadros de compreensão dos discursos/políticas de formação dos professores e de currículos.

\section{CONSIDERAÇÕES FINAIS}

No livro Foucault, Deleuze (197-) afirma que uma instituição comporta enunciados, como uma constituição, contratos, inscrições e registros, e os enunciados remetem a um meio institucional sem o qual eles não poderiam ser formados. Essa relação foi observada na cartografia das práticas discursivas nos dossiês analisados. A produção tem lugar, tem um local. E diríamos um local centralizado. Autores como Sidone, Haddad e Mena-Chaco (2016, p. 17) já indicavam a predominância da localização espacial no que tange à produção científica, mostrando que a geografia da produção “[...] científica no país é marcada por intensa heterogeneidade espacial, com concentração sistemática da produção e dos fluxos de conhecimento nas regiões Sudeste e Sul, com destaque aos estados que sediam universidades públicas”. Entretanto, observamos que os dossiês analisados, rompem com essa lógica, desviando a produção para o eixo Sudeste e Nordeste.

Isso, de certa forma, denota a relação das regiões e instituições na produção da pesquisa educacional, sobretudo no campo do currículo e formação docente, bem como a influência dos grupos de pesquisa dessas instituições na constituição de uma discursividade ou de um regime de verdade que acabam por exercer/funcionar como uma rede na formulação de formações discursivas.

Esse fato pode ser observado no que tange à abordagem teórico-epistemológica denominada Teoria Pós-Crítica, que vem se firmando como modo outro de discurso que escapa de uma lógica até então dominante, bifurcando caminhos possíveis para a produção científica no campo curricular. Ainda é interessante destacar que, sob a égide dessa denominação, se ancoram diversas correntes. Os termos apresentados nos diferentes artigos como “[...] pós-estrutural, pós-colonial, pós-moderno, pós-fundacional e pós-marxista, ainda que conectados, se referem a estudos distintos, com questões e problemáticas próprias, para [...] a educação e o currículo” (LOPES, 2013, p. 10). 
Assim, com relação à busca da compreensão do engendramento de "regimes de verdade" que, a nosso ver, se constituíam como redes histórico-culturais que propiciam a produção de determinados significados (CARVALHO, 2016), podemos observar que nos dossiês analisados se configuraram como campos de regularidades enunciativas que caracterizam uma formação discursiva, mas tais campos se diferem entre si, e essas regularidades não se apresentam de maneira definitiva (FOUCAULT, 1987).

O movimento produzido entre as diferentes perspectivas que se anunciaram nos artigos aqui denominadas de Teorias Críticas e Pós-críticas - aponta-nos que não devemos buscar uma origem absoluta, uma revolução total, um ponto a partir do qual tudo se organiza ou tudo é extinto. As homogeneidades e heterogeneidades enunciativas se entrecruzam com continuidades, articulações, distanciamentos e diferenças (FOUCAULT, 1987).

Para Foucault (1988), o discurso é veiculação e produção de poder. Pode tanto reforçar esse poder quanto miná-lo ou debilitá-lo. Os discursos são elementos ou estratégias no campo das correlações de força. Nesse sentido, podem existir discursos diferentes e mesmo contraditórios dentro de uma mesma formação discursiva.

O quadro apresentado, em relação às abordagens teórico-epistemológicas e aos autores referenciados, aponta-nos que, apesar da observância de certa formação discursiva em torno das Teorias Críticas e Pós-Críticas, não há algo cristalizado, mas oscilante, e as opções por uma abordagem metodológica, assim como a definição dos conceitos, seguem essa oscilação.

Consideramos, dessa forma, que a produção da escrita dos artigos tem relação com a proposta dos dossiês, traduzindo a necessidade da emergência de novos/outros/possíveis eixos temáticos para que a potência e a diferença que caracterizam os discursos no campo da educação sejam contempladas. As formações discursivas, como já afirmado, são produzidas a partir/em/nas relações de poder, por meio de leis e ou regras de existência em que objetos são nomeados, designados, descritos nas relações afirmadas ou negadas.

A formação discursiva pode, assim, formar o lugar, a condição, o campo de emergência, a diferenciação dos indivíduos, dos objetos, dos estados de coisas e das relações que são postas em jogo pelo próprio enunciado. "O discurso é subtraído à lei do devir e se estabelece em uma intemporalidade descontínua. Imobiliza-se por fragmentos: estilhaços precários de eternidades” (FOUCAULT, 1987, p. 191).Com isso queremos reforçar a ideia de que uma formação discursiva pode definir possibilidades de aparecimento e de delimitação do que dá ao discurso seu sentido, posição ou seu valor de verdade, entretanto esse valor se caracteriza como transitório. 


\section{REFERÊNCIAS}

CARVALHO, J. M. O periódico Inquérito Transnacional de Currículo e o espaço-tempo da hospitalidade cosmopolita e da desconstrução dos estudos no campo do currículo. Trasnational Curriculum Inquiry. 10(1) 2013. Disponível em: http://nitinat.library.ubc.ca/ojs/index.php/tci

- Discursividade sobre currículo da comunidade acadêmico-científica vinculada às associações do campo e veiculada em periódicos nacionais e internacional. Projeto de pesquisa. Vitória, 2016.

GERONE JUNIOR, A.; HAGE, S. A. M. Ação pedagógica de professores em escolas ribeirinhas da Amazônia. Teias. Rio de Janeiro, v. 14, n. 33, 2013.

GIOVEDI, V. M. Violência curricular na escola pública: conceito e manifestações. Teias. Rio de Janeiro, v. 14, n. 33, 2013.

DELEUZE, G. Foucault. Tradução de José Carlos Rodrigues. Lisboa: Veja, [197-].

FERREIRA, M. G.; SILVA, J. F. Perspectiva pós-colonial das relações étnico-raciais nas práticas curriculares: conteúdos selecionados e silenciados. Teias. Rio de Janeiro, v. 14, n. 33, 2013.

FOUCAULT, M. Microfísica do poder. Rio de Janeiro: Graal, 1986.

. A arqueologia do saber. 3. ed. Rio de Janeiro: Forense Universitária, 1987.

. História da sexualidade I: a vontade de saber. 7. ed. Rio de Janeiro: Graal, 1988.

Ditos \& escritos 1. Rio de Janeiro: Forense Universitária, 1999.

LOPES, A. C. Teorias pós-críticas, política e currículo. Educação, Sociedade \& Cultura, n. 39, p. 7-23, 2013.

OSÓRIO, M. R. V. ... agora, é a gente com a gente mesmo! Teias. Rio de Janeiro, v. 15, n. 39, 2014.

REIS, L. R. inflexões sobre a vitalidade e o cuidado na época do biopoder: a emergência do biocurrículo. Teias. Rio de Janeiro, v. 16, n. 43 (2015)

SANTOS, I. A. C. Biopotências curriculares: resistências em cenários biopolíticos. Teias. Rio de Janeiro, v. 16, n. 43 (2015)

SAUL, A. M., SAUL, A. Mudar é difícil mas é necessário e urgente: um novo sentido para o projeto político pedagógico da escola. Teias. Rio de Janeiro, v. 14, n. 33, 2013.

SIDONI. O. J. G.; HADDAD, E. A.; MENA-CHALCO, J. P. A ciência nas regiões brasileiras: evolução da produção e das redes de colaboração científica. In: TransInformação, Campinas, v. 28, n. 1, p. 15-31, jan./abr. 2016.

SIKILERO, C. T., THOMAS, A. S. Pacto pela aprendizagem: estratégia biopolítica de governo da aprendizagem.

Teias. Rio de Janeiro, v. 16, n. 43 (2015) 


\section{RESUMO}

Analisa práticas discursivas do periódico Teias, organizado em forma de dossiê pela Associação Brasileira de Currículo, entre 2013 e 2016. Identifica as temáticas dos artigos, autores e filiação institucional, conceitos, abordagem teórico-epistemológica, metodológica e autores referenciados. Utiliza, como metodologia, a análise da discursividade a partir do mapeamento cartográfico-discursivo. Aponta o eixo de produção na Região Sudeste e a predominância de trabalhos fundamentados nas Teorias Crítica e Pós-Crítica, discutindo as relações entre a abordagem metodológica e a epistemológica. Destaca Freire e Foucault como os autores mais referenciados. Ressalta a necessidade da emergência de outros possíveis eixos temáticos, para que as diferenças que caracterizam as práticas discursivas no campo curricular sejam contempladas.

Palavras-chave: Diferença. Docência. Currículo.

\section{THE JOURNAL TEIAS AS A PRODUCTION SPACE IN THE FIELD OF EDUCATION, CURRICULUM AND TEACHER TRAINING}

\section{ABSTRACT}

It analyzes discursive practices of the Teias journal, which was organized in a dossier format by the Brazilian Curriculum Association between 2013 and 2016. It identifies the themes of the articles, authors and institutional affiliation, concepts, theoretical and epistemological approaches, methodology and quoted authors. It uses discourse analysis as methodology, base on cartographic-discursive mapping. It points the Southeast region as the main article producing area and the predominance of papers grounded in the Critical and Post-Critical theories, discussing the relations between the methodological and epistemological approaches. It highlights Freire and Foucault as the most quoted authors. It emphasizes the emergencial need of other possible thematic axes, so that the differences that distinguish the discursive practices in the curricular field are addressed.

Keywords: Diferences. Teaching. Curriculum.

\section{EL PERIÓDICO TEIAS COMO ESPACIO DE PRODUCCIÓN EN EL CAMPO DE LA EDUCACIÓN, CURRÍCULO Y FORMACIÓN DOCENTE}

\section{RESUMEN}

En el presente trabajo se analizan las prácticas discursivas del periódico Teias, organizado en formade dossier por la Asociación Brasileña de Currículo, entre 2013 y 2016. Identifica las temáticas delos artículos, autores y filiación institucional, conceptos, enfoque teórico-epistemológico, metodológico y autores referenciados. Utiliza, como metodología, el análisis de la discursividad a partir del mapeo cartográfico-discursivo. En el presente trabajo se analizan las relaciones entre elenfoque metodológico y la epistemológica, discutiendo las relaciones entre el enfoque metodológico y la epistemológica. Destaca Freire y Foucault como los autores más referenciados. Resalta la necesidad de la emergencia de otros posibles ejes temáticos, para que las diferencias que caracterizan las prácticas discursivas en el campo curricular sean contempladas.

Palabras clave: Diferencia. Enseñanza. Plan de estudios. 